\title{
Recording of community violence by medical and police services
}

\author{
I Sutherland, V Sivarajasingam, J P Shepherd
}

Injury Prevention 2002;8:246-247

See end of article for authors' affiliations

Correspondence to: Dr lan Sutherland, Department of Oral Surgery, Medicine and Pathology, University of Wales College of

Medicine, Heath Park,

Cardiff, CF14 4XN, UK;

sutherlandi3@cardiff.ac.uk
Objectives: To determine the extent to which community violence that results in injury treated in emergency departments appears in official police records and to identify age/gender groups at particular risk of under-recording by the police.

Methods: Non-confidential data for patients with assault related injury treated in the emergency departments of two hospitals in one South Wales city (Swansea) during a six month period were compared with data relating to all recorded crimes in the category "Violence against the person" in the police area where the hospitals were located.

Results: Over the six month period a total of 1513 assaults were recorded by Swansea emergency departments and the police (1019,67.3\% injured males and $494,32.7 \%$ injured females). The majority of these assaults $(993,65.6 \%)$ were recorded exclusively by emergency departments; $357(23.6 \%)$ were recorded only by the police and $163(10.8 \%)$ were recorded by both emergency departments and the police.

Equal proportions of males $(67.3 \%)$ and females $(67.5 \%)$ injured in assaults were recorded by both emergency departments and the police, but men were more likely to have their assault recorded exclusively in emergency departments (odds ratio (OR) 2.1, 95\% confidence interval (CI) 1.7 to 2.7) while women were more likely to have their assault recorded exclusively by the police (OR $2.5,95 \% \mathrm{Cl} 2.0$ to 3.2$)$.

There were no significant relationships between exclusive emergency department recording and increasing age (OR 1.0,95\% $\mathrm{Cl} 0.9$ to 1.2 ), exclusive police recording and increasing age (OR 1.1, $95 \% \mathrm{Cl} 1.0$ to 1.2 ), or between age and dual recording (OR $0.9,95 \% \mathrm{Cl} 0.8$ to 1.0 ).

Conclusions: Most assaults leading to emergency department treatment, particularly in which males were injured, were not recorded by the police. Assaults on the youngest group (0-10, particularly boys) were those least likely to be recorded by police and females over age 45 , the most likely.

Emergency department derived assault data provide unique perspectives of community violence and police detection.
S uccessive international crime surveys have all found that a substantial proportion of violent crime does not appear in official crime statistics. ${ }^{1}$ Consistent with this, it has been found that only about $25 \%-50 \%$ of assaults that result in medical treatment are recorded by the police ${ }^{2}$ and that recording cannot be predicted on the basis of injury severity. ${ }^{3}$ This under-recording is important in both primary and secondary care because it indicates that there is potential for emergency departments to contribute substantially to community violence prevention. This study was performed to find out if there were age and gender differences in emergency department and police recording of assaults. A breakdown by age and gender was considered important as it would serve to help emergency department and police identify potentially vulnerable groups.

\section{SUBJECTS, METHODS, AND RESULTS}

Non-confidential data for patients with assault related injury treated in the emergency departments of Morriston and Singleton hospitals, Swansea, in a six month period, l November 1999 to 30 April 2000 were compared with data relating to all recorded crimes in the category "Violence against the person" in the central Swansea police catchment area (Castle Ward beat) for the same period. Data from both sources included age, gender, and date/time of the assault. Location data were more detailed and comprehensive for assaults recorded by the police, but recording of location by area in emergency department records allowed cross referencing with police data.
Issues of co-terminosity were then addressed and persons were excluded whose assault took place outside the city centre and adjoining areas.

Logistic regression was used to ascertain odds ratios (OR) and confidence intervals (CI).

Over the six month period a total of 1513 assaults were recorded by Swansea emergency departments and the police, in which 1019 (67.3\%) males and 494 (32.7\%) females were injured/victims. The majority of these assaults (993, 65.6\%) were recorded exclusively by emergency departments; 357 $(23.6 \%)$ were recorded only by the police and $163(10.8 \%)$ were recorded by both emergency department and the police. Of all males who had been assaulted, $71.3 \%$ had their assault recorded only by emergency departments compared with $53.9 \%$ of females (OR 2.1, 95\% CI 1.7 to 2.7 ). However, $17.9 \%$ of males had their assault recorded only by the police compared with $35.4 \%$ of females (OR $2.5,95 \%$ CI 2.0 to 3.2 ). Equal proportions of males and females had their assault recorded by both emergency department and the police (10.8\%, 10.7\%; OR 1.0, 95\% CI 0.7 to 1.4 ).

Increasing age made no difference to the proportions of people who had their assault recorded only in the emergency department (OR 1.0, 95\% CI 0.9 to 1.0 ) nor were more recorded exclusively by the police (OR 1.1, 95\% CI 1.0 to 1.2 ). No age differences were found for co-recording by both

Abbreviations: $\mathrm{Cl}$, confidence interval; OR, odds ratio 

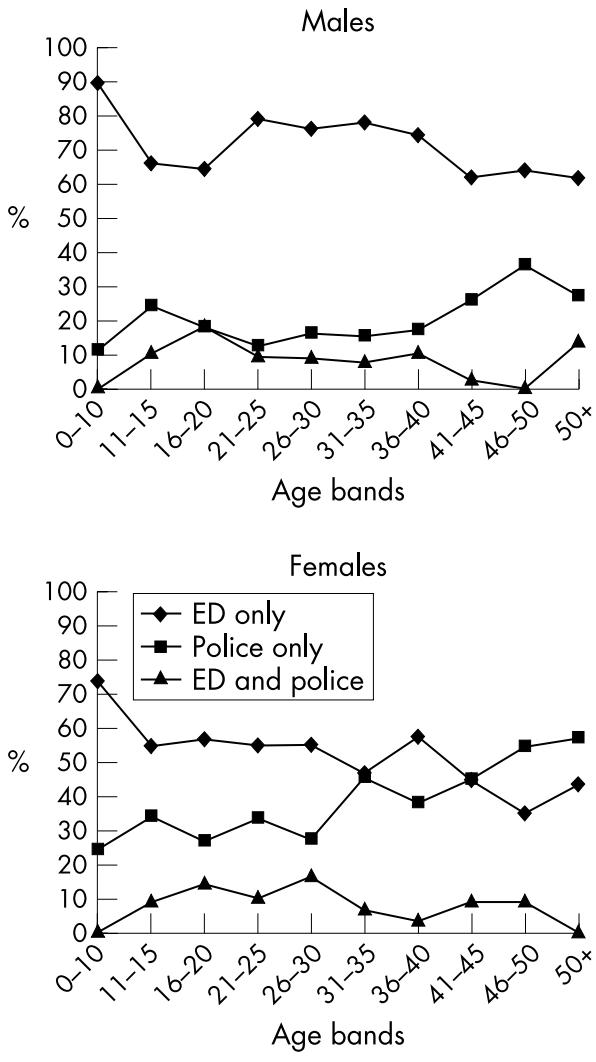

Figure 1 Injuries recorded to police and/or an emergency department (ED) by age and gender.

emergency department and the police (OR 1.0, 95\% CI 0.9 to 1.0) (fig 1).

There were no significant relationships between emergency department recording and increasing age or gender (OR 1.1, 95\% CI 1.0 to 1.2 ) or between police recording and increasing age or gender (OR 1.1, 95\% CI 1.0 to 1.2 ). No age or gender specific differences were found for dual recording either (OR $1.1,95 \%$ CI 0.9 to 1.3 ).

The group most likely to have an assault recorded by both emergency department and the police were 46-50 year old males $(36.7 \%)$. However, none of the $0-10$ year olds of either gender (four boys; nine girls) had their assault recorded by both agencies. Young males aged 0-10 were the group most likely to have their assault only recorded by the emergency department $(89 \%)$, while older females aged $46+$ were the group most likely to have their assault recorded only by the police $(55.8 \%)$.

\section{DISCUSSION}

Overall these results show that little community violence appears in the records of both emergency departments and the police: a large majority of assaults in this study resulted only in emergency department recording. In this study the Swansea police area studied was not precisely co-terminous with the emergency department catchment area. However, as a large proportion of violence is known to take place within city centres, ${ }^{4}$ this study would have been expected to identify differences in recording rates of violent crime by emergency department and the police. Although the emergency departments and police catchment areas are not precisely coterminous, police records included the precise locations of the assaults and the vast majority took place in Swansea city centre: an area served by the two study emergency departments.
It is important to note that the term "recorded", when referring to the police data, means incidents that were actually logged as crimes by the police and which are included in official crime statistics. This is not the same as "reported". Incidents may be reported, but, for various reasons, may not be "recorded". It has been found that differences between actual and recorded crime are due, in large part, to lack of reporting, even of some serious offences, because of the victim's perceptions that the assailant is not identifiable; the victim's habituation to violence; the victim's reluctance to have their own conduct scrutinised; the social costs associated with reporting violence to the police and fear of reprisals.

An accurate knowledge of crime levels, particularly those resulting in injury are vital for local, regional, and national policy makers responsible for combating violent crime. From these data it appears that emergency department data may be more valuable than those recorded by the police in relation to the overall size of the problem of community violence and the extent to which males and females of different ages are affected. Importantly, injury data derived from emergency departments are the only continuous source of information about victimisation in violent crime and should be used to supplement national snapshots obtained by large scale government funded victim surveys.

Politically, emergency department data could facilitate improved targeting of hotspots of violence by police services and provide a new objective measure of violence, using data from outside the criminal justice system. ${ }^{67}$ Emergency department data would have to be prepared in a format compatible with that used by the police and disclosed on a regular weekly or monthly basis. The question of confidentiality is not a serious problem in this context as all data could be anonymised and be confined to time/location and severity of assault/injury. ${ }^{8}$

Apart from the UK, where this health services contribution to violence prevention is being developed, ${ }^{8}$ there appears to be almost no international, systematic, ethically sound emergency department and police collaboration. As appreciation of the substantial extent to which assaults which result in emergency department treatment are not detected by police services, this seems certain to change.

\section{Authors' affiliations}

I Sutherland, V Sivarajasingam, J P Shepherd, Violence Research Group, Department of Oral Surgery, Medicine and Pathology, University of Wales College of Medicine, Cardiff, UK

\section{REFERENCES}

1 Mayhew P, Van Dijk J. Criminal victimisation in eleven industrialised countries - key findings from the 1996 international crime victims survey. Amsterdam: Ministry of Justice, 1997.

2 Shepherd JP, Sivarajasingam V, Rivara FP. Using injury data for violence prevention. BM 2000;321:1481-2.

3 Shepherd JP. Violence: the relation between seriousness of injury and outcome in the criminal justice system. J Accid Emerg Med 1997:14:204-8.

4 Shepherd JP, Brickley M. The relationship between alcohol intoxication stressors and injury in urban violence. British Journal of Criminology 1996;36:546-66

5 Clarkson C, Cretney A, Davis G, et al. Assaults: the relationship between seriousness, criminalisation and punishment. Criminal Law Review 1994;4-21.

6 Shepherd JP. Emergency medicine and police collaboration to prevent community violence. Ann Emerg Med 2001;38:430-7.

7 Shepherd JP. Criminal deterrence as a public health strategy. Lancet 2001;358:1717-22.

8 Crime Reduction Unit. Cardiff Violence Prevention Group. London: Home Office, 2000 